\title{
SOCIO-HEALTH CONTEXT AND PRACTICE OF PELVIC MUSCLE REHABILITATION IN MOROCCO
}

\author{
Hanane Niya ${ }^{1 *}$, Amina El Nousaadani², Mohamed Radid $^{1}$
}

\begin{abstract}
${ }^{1}$ Materials Physics Chemistry Laboratory, The Faculty of Sciences Ben M'Sik, Hassan II University of Casablanca. Morocco.
${ }^{2}$ Regional Centre for Education and Training Professions CRMEF- Casablanca-Settat - Morocco;

*Correspondence: hanane.niya@gmail.com; Tel.: +212 668057037
\end{abstract}

\begin{abstract}
The high rate of maternal mortality (112 per 100000 new births)[29], as well as the maternal health problems observed at the level of health facilities, place maternal health at the center of the concerns of ministerial decision-makers in Morocco.. At the same time, the issue of maternal morbidity remains less addressed and documented in comparison to mortality, despite its frequency and its significant consequences of social and family rejection of women. These observations have led us to wonder about the management of morbidity during childbirth and postpartum, in particular the practice of pelvic muscle rehabilitation PMR, which is still absent in public health establishments in Morocco. What are the reasons for this deficit in the prescription of perineal rehabilitation? This question of understanding guided us to study the socio-cultural context, representations around the epistemology of the body within Moroccan Arab-Muslim society, to link them to this re-educational gap. The semi-structured interview tool with diversified populations highlights an organizational and strategic dysfunction despite the efforts made by the Ministry of Health, linked to the lack of awareness and training of health professionals, as well as to the inadequacy of pre, per and especially postnatal care. At the same time, the responses of patients with pelvic floor dysfunction PFD refer to the socio-marital repercussions as well as impairments of the body schema, representations of self and self-esteem, altering their quality of life.
\end{abstract}

Keywords: Pelvic Muscle Rehabilitation PMR; maternal morbidity; postpartum, Morocco.

\section{Introduction}

In Morocco, and like in other developing countries, interest in maternal health has only started to gain momentum since the International Conference on «Safe Motherhood », held in Nairobi in 1987 [15].

Attention has therefore been drawn above all to maternal mortality, the rate of which is considered to be among the highest in developing countries despite the great efforts made by the Ministry of Health. Estimated at 227 per 100,000 live births in 2007 and 112 in 2015 [28, 29]. Yet this maternal mortality is only the tip of the iceberg of the overall maternal health problems [5].

In contrast, maternal morbidity defined by the World Health Organization (WHO) as « a pathological condition in a woman who is or has been pregnant, aggravated by pregnancy or its treatment » [31] or in a simpler way, any pathological condition that appears during pregnancy, childbirth and postpartum [27, 11] remains very little discussed and treated in Morocco.

The WHO estimates that maternal morbidity is 6 to 10 times more frequent than maternal mortality. She also considers that certain perineal disorders such as incontinence and involuntary urine leakage, which constitute a social and hygiene discomfort, can leave sequelae which frequently lead to social and family rejection of women [26].

\section{Context}

In Morocco and until now, the practice of PMR remains absent in all public health establishments. Moroccan women who have given birth do not benefit from any postpartum perineal rehabilitation session, even though they sometimes have postnatal PFD.

Despite the multiple and perpetual efforts of the Moroccan government, our public health strategies do not fully meet the needs of reproductive health" ${ }^{1}$ a general state of physical, mental and social well-being in all matters relating to the genital system, its functions, its functioning, and not only the absence of disease or

\footnotetext{
${ }^{1}$ International Conference on Population and Development, Cairo, 5-13 September
}

\footnotetext{
* Corresponding author: hanane.niya@gmail.com
} 
infirmity" [16] and we find it difficult to objectify it into operational activities and program development, such as for pre and postnatal PMR.

Our initial astonishment for this research is linked to our own professional experience in the public hospitals. We had the opportunity to see, in postnatal consultation, patients who present pelvic floor dysfunction PFD related to pregnancy and delivery, such as: urinary incontinence, dyspareunia and pelvic organ prolapse POP, without PMR.

\subsection{Social issues:}

Unfortunately, the extent and prevalence of reproductive morbidity remain poorly documented, according to the ENSME « National Survey on Mother and Child Health in Morocco » carried out in 1997 by the Ministry of Health, $29.2 \%$ of women presented at least one symptom of maternal morbidity [24].

We would like to emphasize that despite our multiple researches and our dismay at the poor documentation on studies relating to maternal morbidity and its management at the national level, it is our experience with some patients who have a lot marked our journey which has always encouraged us to dig more.

Affected by some clinical cases of patients, in whom postnatal bodily and physical complications subsequently took on another psycho-social dimension, with significant consequences such as: divorce, polygamy and social marginalization with a sense of invalidity and infirmity in these patients.

Our affect as researchers has increased, by wanting to do something with regard to these women, to broaden our scope of practice and to nourish our power to act ${ }^{2}$ as professionals in our work environment, especially in the absence; in all public health establishments; of PMR which represents the simple conservative treatment for PFD $^{3}$ [31].

\section{Problematic}

Following the frustration during our professional experience and after training in Women's Pelvic floor and real field training courses in perineal rehabilitation in Paris - which allowed us to acquire the required professional skills and resources for the practice of PMR in France - [22] we considered it important even before transposing this practice to the Moroccan population, to first understand the socio-cultural and health context as well as the different representations about the epistemology of the body within Moroccan society. To

\footnotetext{
2 This concept, first used in 1997, is part of a perspective explored by Spinoza and Ricoeur (Clot, 1999b). It unifies concepts around possible or impossible developments in action (Clot, 1995).

${ }^{3}$ According to National Agency for accreditation and Health evaluation [ANAES], 2002, P. 10
}

understand why there is a deficit in the prescription PMR as a task in public health establishments in Morocco.

What are the obstacles to the practice of PMR, despite the demand of women in postpartum? «The impediments to action are often at the root of the requests addressed to us [...] So we try to make this suffering a way to act » [14].

Our research object is to understand why until today perineal rehabilitation is not practiced in the public sector in Morocco.

\section{The concepts used}

\subsection{Prescription deficit:}

In our field of service practice, the Ministry of Health entrusts us as midwives, women who have given birth for postnatal consultation and asks us to do our best by carrying out several prescribed tasks, ensuring for each woman her clinical examination with recording vital signs, contraception awareness and breastfeeding.

However, the practice of PMR is never prescribed and remains absent in postpartum, it is characterized by a lack of prescriptions. It may be infinite and unattainable following a deficit of the means to achieve it. We are typically in the situation where "the prescription is infinite and the under-prescription of the means to reach them is total" [17].

During our professional activity, «Man is full of unrealized possibilities every minute »[32] and this is what develops in order to carry out the prescription, as is the case with perineal rehabilitation. Hence the need, on the part of those responsible for maternal health in the public sector in Morocco, to think about designing a prescription as well as the resources to implement to achieve this task.

Our aim is to be able to participate subsequently in the realization of a prescription by the ministerial department responsible for maternal health "an injunction to do, issued by an authority" [18] and a didactic area for this practice.

In this example of the prescription deficit, the prescription that will come later will not be a «topdown» prescription coming from the organizational structure, but rather a «back-up» prescription, coming from matter which has its laws and which tends to make the law. The "matter" of the work in this case is human: it comes from the client but also from the professional: patients with PFD after pregnancy and childbirth who need to be treated with PMR for a better quality of life, but also from the health professionals concerned by this practice who have their theoretical background but who have never benefited from a in-depth methodological and practical training and who do not have the necessary equipment either. 
What we are looking for is to summon something new in our practice based on the old, on what we have discovered from our activity, and the patterns of our experience which represent a stock of ready-to-act for the design of a didactic space for the practice of perineal rehabilitation in Morocco. We would like to make our already done experience available for experiments to be done and as Vygotsky says in awareness: lived experience of lived experiences. In other words, the object lived yesterday is promoted to the rank of means for experiencing the present or future situation «Being aware of your lived experiences is nothing more than having them at your disposal »[32,33]

\subsection{Activity prevented:}

In addition to the concept of deficit and lack of prescription, the concept that Y. Clot calls prevented activity, seems very important to us to mobilize during this study, because we need to understand the reality of the activity of midwives responsible for post-natal care, to understand what should be done, what could have been done, what is to be done, what we are trying to do, and what we think we can do elsewhere as midwives. "What we try to do without success and which escapes us, what we refrain from doing, in other words the activities that are suspended, prevented" [13, 14]. We will see later why the practice of PMR, which represents the overdue part (awaiting completion) of the activity of midwives, is suspended or prevented.

\subsection{The epistemology of the body:}

It is very interesting, for this exploratory study, to also look at the concept of the 'epistemology of the body' and the different representations around the body in Moroccan Arab-Muslim culture, which is still influenced and codified by the foundations of Islam and Moroccan traditions, where modesty is a custom that has always been attached to femininity. Especially when the subject in question revolves around the woman's perineum, which represents an organ of the body "damaged" by pregnancy and delivery.

It is important to understand how the body is made as an object of research, but in its complexity, "it merges neither with its biological reality, as a living organ, nor with its imaginary reality, as a fantasy, nor with its social reality as cultural configuration and practices. It's in a way, all three at the same time" [9], to identify the underlying preconceptions which are at the origin of all research on the body, what Jean Duvignaud calls the "subtext" [18].

In this work, we have tried to study the body as an interdisciplinary object, as a mobile, dynamic and living object for which knowledge is emergent "[2,3]. But also to study the body of women after pregnancy and delivery as a subjective object on and in which reflexivity acts in representation, this by the interview chosen as a methodological tool which allows us to discover different cultural interpretations around the body itself, the lived body, the social body, the body schema and the body image, by taking into account the part of the self and the involvement of those around you and others in the making of the body as an object. Also by taking into consideration the inflexible specificity of the human body and its matter which includes sex, blood, organs, childbirth ... and which thus represents an outside but also an inside, that is to say an intention and an expression of what we see and what we do not see, of the perceptible and the imperceptible ... [3, 4].

\section{Materials and methods}

Our research was carried out at the Provincial Hospital of Inezgane/Agadir, health centers and birthing centers in the region of Agadir, as well as at the maternal health protection service of the Ministry of Health.

For this study we worked upstream of professional didactic while drawing inspiration from training engineering, particularly the needs analysis stage which is at the heart of our problem to understand the sociohealth and cultural issues, the lack of prescription in PMR, as well as the different representations around the body in the Moroccan culture. This in the aim to design subsequently: a didactic area adapted for this practice in Morocco.

\subsection{Methodological investigation tool:}

The objective in carrying out this research project was to understand first of all the socio-cultural and health issues and the deficit in the perineal reeducation prescription, also to discover how the body and its epistemology are represented within my culture and to analyze its representations, in order to create a didactic area for this practice later on.

In order to achieve this objective, we adopt the "semidirective interview" for data collection, which is a tool that predates the methods of the human and social sciences and whose reference to the author Carls Rogers is very frequent. According to this great American psychologist and initiator of the Person-Centered Approach (PCA), the use of the interview surpasses the therapeutic framework to reach the communication framework which allows the interviewee to freely express problems, memories, family and professional life [12]. 
For Goffman, who represents a current of symbolic interactionism ${ }^{4}$, the interview is a situation of social interaction, but also a situation of representation which he calls "face-work", which includes the ritual character to keep face and also the issue of social relations, " anything a person does so that their actions do not cause anyone to lose face » [20]. According to Goffman, in any interview and therefore in any interaction, the participants seek to convey a certain image of themselves or, in his words, try to put on a « good face ». This figuration through the preservation of the face of others, from the definition of the situation that each actant makes, and which evolves during the interaction, according to the social attributes and the appreciations and judgments that each brings to the during the meeting $[19,21]$.

In the same interactionist trend, Brès underlines that the interview falls under the category of verbal interaction and stems from a co-construction and a co-enunciation [10]. For him, the development of statements during an interview is determined by the fact that they come from someone and that they are directed towards someone else. What Bakhtin takes up by recalling that «every word spoken has two sides and that it is precisely the product of the interaction of the speaker and the listener » [6]. Otherwise, an interview is constructed from the different behaviors we produce towards the other, such as our rephrasing, our validation or reminder marks during the interview. This also gives the interaction relatively asymmetrical roles: one who manages the interview, leads the alternating turns of speech and asks questions and the other who answers.

The choice of this methodology is justified by the target of our research, which can be placed within the framework of a pre-investigation phase essential when working in a new field of research or when the culture studied is different, the aim of our research around perineal reeducation which is a new specialty and in a different Moroccan culture, with its traditions and customs. This tool allows us more exploration, control, verification and deepening. Indeed, in our needs analysis, it seemed useful to us to meet and interview the different actors directly in the field, following a framework of predefined themes which will allow us to have a thematic focus, while allowing ourselves to ask new questions in the interview to highlight the priorities of the interviewees. The interviews were recorded using a digital Dictaphone, something that switches from private speech to public speech, which can be used, which can be embarrassing for the interviewee. According to Brès, the Dictaphone represents an "absent third party", which means that the words are not only

\footnotetext{
${ }^{4}$ Preferring to meanings spontaneously elaborated by the authors during their interactions. Goffman, E., L'Asile, Paris, Éditions de Minuit, 1968, 451 pp.
}

addressed to the speaker, but will be reworked and, as the interviewee may think, will be analyzed [10].

After the fieldwork, it is the transcription of the collected data that follows, to move from the verbal content collected orally to a written support ready to be analyzed. This operation is even more complex when the interviews are conducted in a language other than the language of writing, which requires a translation in addition to the transcription. We specify that the interviews are carried out in dialectal Arabic and sometimes even in Berber, with the aim of making the interviewees more comfortable, while maintaining the specificities linked to the sociolinguistic situations concerned.

\subsection{Population and sample:}

This study is part of a qualitative approach whose main objective was not to establish a representative sample of morbid patients, already due to the lack of statistics and research on maternal morbidity and perineal rehabilitation in Morocco, but the aim was above all to describe the different representations around the body and the rehabilitation of the intimate.

The sample studied is represented by 31 interviewees.

- 15 semi-directive interviews were aimed at Moroccan women who have different perineal complications related to pregnancy and childbirth such as: urinary incontinence and dyspareunia

- 15 semi-directive interviews were addressed to health professionals involved in the practice of perineal reeducation, namely: midwives, gynecologists obstetricians and physiotherapists.

- A final non-directive interview with the head of the Department of Maternal Health at the Ministry of Health.

\subsection{Conducting the interview:}

Several elements were taken into account before proceeding with the interview. It is important to ask for the possibility and permission to record and to explain the conditions of confidentiality:

- For patients with PFD, the choice of recording was made on the basis of anonymity and voluntariness and of course by first establishing a climate of trust with the patients with whom we tried to investigate, in an exploratory perspective, their personal, sensitive, intimate and confidential data, in a context of ethical respect. 
- Likewise for the health professionals concerned by the practice of perineal rehabilitation, the interviews were carried out in accordance with the rules of ethics: the rule of information, consent, confidentiality and the use of information collected in the context of research and which will only be used for research purposes.

For this type of interview, which is neither totally closed nor totally open, and which according to Campenhoudt and Quivy is the form most often used by researchers to discover and deepen their knowledge of a field with a plan or "canvas", the themes to be addressed are fixed in advance with a series of relatively open-ended guiding questions which do not necessarily follow the same order of the pre-established grid, we respect as much as possible the logic that suits the interviewee [30].

After each interview, and before moving on to transcription, which is a form of written fixation of the interaction and textualization of what happens in the language exchange, we were interested in noting the climate of the interview process, the non-verbal, our impressions as researchers, and also the synthesis and key words of the interview.

On the other hand, for the interview conducted with the person responsible for maternal health, we opted for the non-directive and non-standardized free interview, with the aim of reaching deeper levels of attitudes and opinions, since this type of interview allows maximum freedom of subject matter. By this choice of nondirective interview, we aimed to grant a more active role to the interviewee who is, normally, recognized capable of speaking legitimately on the proposed topic, taking into consideration his competence concerning the various aspects of the problem.

\subsection{Data analysis:}

After the fieldwork and as a first step, the transcription of the recorded interviews is already part of the analysis. It is important to understand the speech of interviewee in its rhythm, prosody, nuance and all its complexities. In addition to the words spoken by the interviewee; the silences, the body attitudes, the hesitations and the pauses which characterize the tone of the interviews are very important and make the interviews richer and more interpretable. Even though generally speaking, the fidelity of an interview cannot be fully respected by transforming the spoken word into written form, because we do not write as we speak and therefore the spoken word can lose some of the richness of the interaction, even more when a translation is necessary. Respecting this fidelity is even more difficult when the interviews are carried out in another foreign language and a translation is necessary.

After the transcription of the verbal speech, the paraverbal and non-verbal information of the collected material, we subsequently treated it by a thematic classification after the analysis of the content which is " a set of communication analysis techniques aimed by description of the content of statements to obtain indicators allowing the inference of knowledge relating to the conditions of production/reception of these statements" [7, 23].

Thematic analysis is the most used method for the treatment of semi-structured interviews; it consists in counting the themes or items of meaning in the coding units by noting the frequency of predefined themes which appear in verbal and textual expressions under various more concrete contents. This method, which consists in identifying the occurrence of general themes, involves a categorization whose basic unit is the theme5, which is defined as «an affirmation on a subject» [8]. In other words, it is a summary or a sentence from which several singular formulations can be attributed [7].

\section{Results}

To be more efficient in the use of the data collected, we produced thematic interpretation tables, identifying for each sequence the existing thematic categories and making links between the different themes in order to be able to draw conclusions later. This analysis was applied to the entire corpus collected.

In the beginning, we worked on 25 sub-themes and thematic categories, which we then grouped into seven general themes:

Five themes to identify the reasons for the prescription deficit:

- Ministerial organization

- Weight of culture/social-cultural barrier

- Lack of training for professionals

- Lack of awareness

- Pre-, per- and post-natal care

A general theme around the epistemology of the body and the impact of perineal morbidity on the image of the body, the schema of the body and the representation of the self:

- Impact of maternal morbidity

A seventh and last general theme that was very recurrent:

- Interest in PMR

Table 1. Formatting sections, subsections, and subsubsections

\begin{tabular}{|l|l|l|}
\hline Object & General Topics & Sub Topics \\
\hline & & \\
\hline
\end{tabular}




\begin{tabular}{|c|c|c|}
\hline \multirow{5}{*}{ 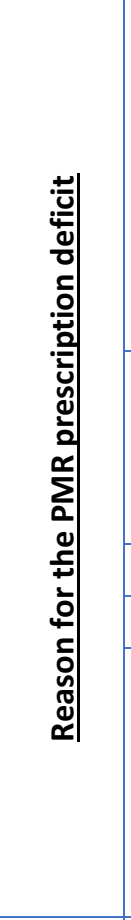 } & Ministerial Organization & $\begin{array}{l}\text {-Failure of postnatal } \\
\text { monitoring. } \\
\text {-Lack of preparation for } \\
\text { childbirth. } \\
\text {-Workload } \\
\text {-Lack of staff } \\
\text {-Organizational } \\
\text { dysfunction at } \\
\text { ministerial level }\end{array}$ \\
\hline & $\begin{array}{l}\text { Weight of the culture and } \\
\text { social-cultural brake }\end{array}$ & $\begin{array}{l}\text {-Weight of the culture } \\
\text {-Taboo subject } \\
\text {-Expression of its pelvic } \\
\text { morbidity }\end{array}$ \\
\hline & Lack of staff training & \\
\hline & Lack of awareness & \\
\hline & $\begin{array}{l}\text { Pre-, per- and postnatal } \\
\text { monitoring }\end{array}$ & $\begin{array}{l}\text {-Pregnancy and childbirth } \\
\text { monitoring } \\
\text {-Respect of postnatal } \\
\text { consultation } \\
\text {-Dystocia childbirth } \\
\text {-Complication after } \\
\text { delivery and PFD }\end{array}$ \\
\hline 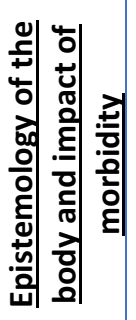 & $\begin{array}{l}\text { Impact of maternal } \\
\text { morbidity }\end{array}$ & $\begin{array}{l}\text { - Pain } \\
\text {-Social life impact } \\
\text {-Marital life impact } \\
\text {-Psychological life impact } \\
\text {-Professional life impact } \\
\text {-Body image and shema }\end{array}$ \\
\hline 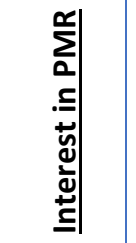 & $\begin{array}{l}\text { Interest in pelvic muscle } \\
\text { rehabilitation }\end{array}$ & $\begin{array}{l}\text { - Importance of PMR } \\
\text {-Demand for PMR } \\
\text {-Recent appearance of } \\
\text { PMR } \\
\text {-Knowledge around } \\
\text { practice of PMR }\end{array}$ \\
\hline
\end{tabular}

In general, the thematic analysis of the whole of the transcribed corpus has enabled us to identify a number of causes relating to the deficit of prescription of perineal rehabilitation and the absence of the practice of this specialty in public health establishments in Morocco.

For the reasons of this prescription deficit, the thematic occurrence is more or less similar between the different general themes, with frequent repetition of the theme of ministerial organization and its strategic dysfunction despite the multiple efforts made by the Ministry of Health in the field of maternal and reproductive health. According to the practitioners interviewed, this is linked to the lack of human resources and access to care, but also to the lack of training for nursing staff.

It is succeeded by the theme of pre, per and postnatal monitoring, which according to the professionals as well as the patients interviewed, suffers from a large failure of care. In fact, $85 \%$ of the women in our sample did not know the location and function of their perineum or its role, and they declared that it was only during delivery (without any prior preparation) that they discover this intimate and sexual part of their body.

\subsection{Weight of the culture}

It is important to underline that the theme of the weight of culture and socio-cultural brake which was approached by all the interviewees, was evoked essentially within the framework of an adaptation of the values of this re-education of the "intimate", as shown in the two extracts below: one is taken from the interview with Mrs N: a patient with postpartum urinary incontinence and the other from the interview with a male physiotherapist.

\section{Of course wot as long as this rehobilitation} will allow we to cor rect mp perine al problem and improve my life as a couple, Im going to.. Im going to [lookfor the word] Im going to do if... [pase and top in intonation] on the other homd I prefer to do it with a woman and wot a man. it is inded an intmate part and and therefore I will be more comfortable with a woman..

Fig. 1. Excerpt from the interview with Ms M

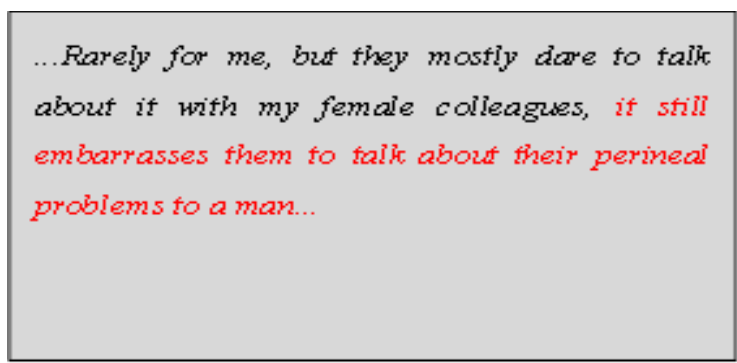

Fig. 2. Excerpt from the interview with physiotherapist

We note that the patient is not at all against the practice of PMR, which she links, moreover, to the improvement of her conjugal life. However, she prefers to be reeducated by a woman and not a man. This is also confirmed by the physiotherapist, who stated that the patients dare to talk about their perineal morbidities to female professionals much more than to male professionals and that they feel less comfortable in front of a male professional.

So we can see that the weight of culture weighs on the choice of the practitioner for the practice of PMR, especially since for this type of practice, the region of the body concerned by the rehabilitation belongs to the person's intimacy: the perineum, which means etymologically "what is around the sacred place", includes a symbolic dimension, which goes beyond the function of reproduction, that of sexuality and sphincter 
physiology. The perineum is a support for the genital parts of the body, but also a seat of the person's identity giving access to what is most intimate in the person. It is a symbolic place that it is forbidden to exhibit and unveil, especially in a Moroccan Arab-Muslim culture influenced by customs and traditions.

\subsection{Impact of maternal morbidity}

For all the patients interviewed, the theme that was repeated frequently was that of the impact of maternal morbidity: it was mentioned 169 times by the 15 morbid women. They all spoke of a damaged body which is combined with a body image altered by their PFD and therefore a degraded representation and self-esteem; knowing that this self-esteem is embedded in the social relationship and influenced by the gaze of the other, hens an impact on social, conjugal, psychological and professional life.

"Yes yes of course, not only my married life but my social life in general, I have become too isolated... when I was sociable and always smiling... now I run away from people... I still have the impression that I smell like urine. . that...that...that I just stink...even my husband I often run away from him... [a long silence]...I feel like a different person...incomplete, [emphasis of voice] I'm no longer normal" (Mrs M, 29 years old, third-parent)

\subsection{Interest in PMR}

All the practitioners involved in the practice of PMR in our sample showed great interest in this conservative treatment of PFD.

Interviewed midwives, physiotherapists and gynecologists all expressed the importance of the practice of PMR. Despite the absence of this specialty in public health establishments in Morocco, they all have theoretical knowledge about this rehabilitative care, the methods used and its role in prevention and treatment of PFD after pregnancy and delivery.

\section{Discussion}

This research allowed us to get an idea of what practitioners and patients with PFD think about the practice of PMR in the Moroccan context. It enabled us to discover that this practice represents a "suspended" and "prevented" task for health professionals[13], with a deficit of prescription due to several issues related to human resources, workload, lack of basic and above all continuous training, awareness and access to care. These results were confirmed by the interview with the head of maternal health, who affirmed that Morocco, and despite the continuous efforts made by the government, has an organizational and strategic deficit with regard to maternal and reproductive health.

Moreover, in Morocco and according to the Sectoral Strategy, 2012-2016, we have a gynecologist for 2,540 expected births and a midwife for 218 expected births
EB. While the WHO recommends a standard of one midwife for $175 \mathrm{~EB}$.

However, the United Nations (UN), of which Morocco is a member, insists on maternal, reproductive and sexual health, which is "fundamental for individuals, couples and families, and for the socio-economic development of communities" and links it to human resources, which it considers to be essential for improving health, hence the importance of training, and the encouragement of specific potential and skills.

Dissatisfaction is common between professionals and patients, especially for those women in whom perineal morbidity has influenced their body image and pattern, as well as the representation of the self that is embedded in the social relationship with others, based also on selfesteem and the narcissistic dimension; that is how the person loves himself in his body in relation to his positive or negative emotional experience. This selfesteem is affected in its entirety in these women by the bodily intrusion of PFD.

After the shock of PFD in postpartum, comes the shock of life. Morbidity can influence many aspects of personality in these women with pelvic floor problems. Sometimes they appear to be others, no longer themselves. For these patients, there is a painful bodily experience, with a notion of the "damaged" and dysfunctional body that will upset the relationship to oneself, to others and especially to the spouse, which then deteriorates, giving rise to more complex forms of psycho-social consequences, such as divorce, polygamy, marginalization and social rejection.

To overcome this lack of postnatal monitoring and care, the Ministry of Health has introduced a new approach, which is the "mothers' classes" approach. This consists of organizing sessions between pregnant women and women who have given birth to raise awareness of the importance of pre-, per- and postnatal monitoring and especially postnatal consultation to diagnose possible maternal morbidities.

Also, since the 5th National Survey on Population and Family Health (EPSF) carried out in April 2012 and whose aim was to improve the policies and strategies of the Ministry of Health, the subject of reproductive health and maternal morbidity has begun to be addressed. Moreover, among the indicators studied by this survey, there is reproductive health with perineal morbidities and problems, such as prolapse and urinary incontinence [25].

\section{Training of health professionals}

The Moroccan health system has undergone a real turnaround in recent years as a result of demographic and socio-economic changes and the reforms implemented by the Ministry of Health. These reforms also concerned the training and practice of health professionals. This has been achieved by the introduction of the LMD system (License-Master-Doctorate) with 
academic equivalence of diplomas and the establishment of bridges with the university.

This revolution, long awaited by health professionals, aims to enhance training in in health sciences, which in requires, on the other hand, a commitment of teachertrainers and researchers for the development of scientific research in health sciences, which is no longer a choice but an obligation to improve the health situation of the population.

\section{Conclusion}

This study has shown us that despite the commitment of the Ministry of Health and the perpetual efforts of the government in maternal and reproductive health, the practice of perineal rehabilitation remains absent in the various public health establishments in Morocco.

This work also allowed us to discover that the current situation of the Moroccan health system, as well as the recent reforms initiated by the Ministry of Health, constitute an opportunity to promote maternal and reproductive health, and improve the quality of care for Moroccan women in postpartum; and consequently, reduce maternal and perineal morbidity as well as the social problems associated with this morbidity.

This opportunity will also allow us to propose the design of a didactic space for the practice of perineal rehabilitation in the public health sector,by adapting it, of course, to the values of the Moroccan population, and respecting their choices, their beliefs and traditions. Also, by raising the women's awareness of the importance of this conservative treatment in pre- and postpartum but above all by improving the quality of the training for midwives and physiotherapists in perineal rehabilitation. This can be achieved by proposing training days focused on active pedagogy of training engineering and adapted to continuing training for the adult.

\section{References}

1. Agence Nationale d'Accréditation et d'Evaluation en Santé. Rééducationdans le cadre du post-partum. Recommandationsprofessionnelles. Paris. ANAES. (2002)

2. B. Andrieu, Le Dictionnaire du corps en SHS. Paris, CNRS Éditions (2006, a)

3. B. Andrieu, Quelle épistémologie du corps ?, Corps, $n^{\circ} 1$, p. 13-21. (2006, b)

4. Andrieu B. (1993), Le Corps dispersé. Une histoire du corps au XXe siècle. Paris, Le Harmattan

5. B.Assarag and M.D. Wilmet, La morbidité maternelle du post-partum au Maroc: Une information nécessaire pour une réponse appropriée. Université Libre de Bruxelles- Ecole de Santé Publique. (2015)

6. D. Bakhtine, Le marxisme et la philosophie du langage, Paris, Editions de Minuit. (1977)

7. L. Bardin, L'Analyse de contenu. Paris : Presses universitaires de France [PUF]. (2001)

8. B. Berelson, Content analysis in communication réseau, The Free Press. (1952)

9. M. Bernard, Le Corps, Paris, Éditions du Seuil, Collection Points, Essais, (1995).

10. J. Brès, « L'entretien et ses techniques », in Calvet, Louis-Jean et Dumont, Pierre (sous la dir.de) L'enquête sociolinguistique, Le Harmattan, 61-76. (1999)

11. O.M.R. Campbell. and W.J. Graham Measuring maternal mortality and morbidity: Levels and Trends, Maternal and child Epidemiology Unit, London School of Hygiene and Tropical Medecine, Publication $n^{\circ} 2$, London, p. 33-54. (1990)

12. R. Carl Le développement de la personne, Paris Dunod (2005)

13. Y. Clot, La fonction psychologique du travail, Paris : PUF(1999)

14. Y. Clot and D. Faïta Genres et styles en analyse du travail: concepts et méthodes. Revue Travailler, $n^{\circ} 4,7$ à 42. (2000)

15. Conférence internationale sur la contribution de la planification familiale à l'amélioration de la santé des femmes et des enfants, Nairobi, Kenya, 5-9 octobre (1987)

16. Conférence internationale sur la population et le développement, le Caire, 5-13 septembre (1994)

17. F. Daniellou, Le travail des prescriptions. 37ème congrès de la Société d'Ergonomie de Langue Française [SELFE] « les évolutions de la prescription 》 Aix-en-Provence. (2002). En ligne: http://www.ergonomieself.org/documents/37eme-Aix-en-Provence2002/daniellou.pdf

18. J. Duvignaud, Le sous-texte. Arles, ActesSud. (2005)

19. E. Goffman, La mise en scène de la vie quotidienne, traduit de l'anglais par Alain Kihm, Paris, les Editions de minuit, , p.12. (1973)

20. E. Goffman, Les rites d'interactions. Paris, Editions de minuit (1974).

21. E. Goffman, Façon de parler. Paris, Editions de minuit,(1987).

22. G. Le Boterf, De la compétence, essai sur un attracteur étrange. Vol.1. Paris, Editions d'organisations. (1995) 
23. M. C. d'Unrug. Analyse de contenu et acte de parole, Editions Universitaires(1974)

24. Ministère de la Santé Maroc, Egypte et Ligue des États Arabes, Enquête sur la population et la santé de la mère et de l'enfant (ENSME), 333 p. (1997)

25. Ministère de la Santé du Royaume du Maroc Enquête Nationale sur la Population et la Santé Familiale [EPSF 2011] Rabat, Direction de la Planification et des Ressources Humaines, Ministère de la Santé du Maroc, 20-30. (2012)

26. Organisation Mondiale de la Sante. Les causes des décès maternels, in Royston $E$. et Armstrong S., La Prévention des décès maternels. Genève, p. 78-111. (1990).

27. Organisation Mondiale de la Sante. Classification statistique internationale des maladies et des problèmes de santé connexes Volume 1, dixième révision, Genève. ird00577825(1993)

28. Organisation Mondiale de la Santé, Fonds des Nations Unies pour l'enfance, Fonds des Nations Unies pour la population et Banque Mondiale. Rapport d'estimation de I'OMS, I'UNICEF, I'UNEPA et la Banque Mondiale, Genève, p.40.(Octobre 2007)

29. Organisation Mondiale de la Santé, Fonds des Nations Unies pour l'enfance, Fonds des Nations Unies pour la population et Banque Mondiale.Rapport d'estimation de I'OMS, I'UNICEF, I'UNEPA et la Banque Mondiale, (2015)

30. R. Quivy and V. CampenhoudtL Manuel de recherche en sciences sociales, Paris : Ed. Dunod. (1995)

31. S. Ren and al, The Effect of Pelvic Floor Muscle Training on Pelvic Floor Dysfunction in Pregnant and Postpartum Women. Physical Activity and Health, 4(1), pp. 130-141. DOI: https://doi.org/10.5334/paah.64. (2020)

32. L.S. Vygotski, La conscience comme problème de la psychologie du comportement. In L.-S Vygotski, Conscience, inconscient, émotion. Paris : La Dispute (2003).

33. L. Vygotski, Le problème de la conscience dans la psychologie du comportement ( $F$. Sève, trad.), Société française, 50 : 35-47. (1994). 